Shock, Publish Ahead of Print

DOI : 10.1097/SHK.0000000000001420

\title{
Stem Cell Therapy and Hydrogen Sulfide: Conventional or Nonconventional Mechanisms of Action?
}

\author{
Amanda R. Jensen ${ }^{1,4}$, Natalie A. Drucker ${ }^{1,4}$, Ken R. Olson ${ }^{4}$ \\ and Troy A. Markel ${ }^{1,2,3}$ \\ ${ }^{1}$ Department of Surgery, Section of Pediatric Surgery \\ ${ }^{2}$ Riley Hospital for Children at Indiana University Health, \\ ${ }^{3}$ The Indiana University School of Medicine, South Bend - South Bend, IN, and \\ ${ }^{4}$ The Indiana University School of Medicine, Indianapolis, IN
}

ARJ performed animal I/R experiments, protein isolation, histological grading and drafted the manuscript, NAD performed histological grading and statistical analysis, KRO performed hydrogen sulfide assays, TAM contributed critical ideas, assistance and manuscript advice. All authors provided critical revisions to the manuscript and assisted with its final preparation.

Running Head: Stem Cells and Hydrogen Sulfide

$\underline{\text { Conflicts of Interest }}$

TAM receives consultation fees from Scioto Biosciences and Onsite, LLC

$\underline{\text { Funding }}$

National Institutes of Health, NIDDK K08DK113226 (TAM)

The Koret Foundation (TAM)

Indiana University Biomedical Research Grant (KRO)

The Department of Surgery at the Indiana University School of Medicine (TAM)

Correspondence:

Troy A. Markel, MD

Assistant Professor of Surgery

Indiana University School of Medicine

Riley Hospital for Children at IU Health

705 Riley Hospital Dr., RI 2500

Indianapolis, IN 46202

This is the author's manuscript of the article published in final edited form as:

Jensen, A. R., Drucker, N. A., Olson, K. R., \& Markel, T. A. (2019). Stem Cell Therapy and Hydrogen Sulfide: Conventional or Nonconventional Mechanisms of Action? Shock (Augusta, Ga.). https://doi.org/10.1097/SHK.0000000000001420 


\section{ABSTRACT}

Purpose: Hydrogen sulfide $\left(\mathrm{H}_{2} \mathrm{~S}\right)$ has many beneficial biological properties, including the ability to promote vasodilation. It has been shown to be released from stem cells and increased by hypoxia. Therefore, $\mathrm{H}_{2} \mathrm{~S}$ may be an important paracrine factor in stem cell mediated intestinal protection. We hypothesized that hydrogen sulfide created through conventional pathways would be a critical component of stem cell mediated intestinal protection following ischemic injury.

Methods: Human bone marrow derived mesenchymal stem cells (BMSCs) were transfected with negative control siRNA (Scramble), or with siRNA to CBS, MPST, or CTH. Knockdown was confirmed with PCR and hydrogen sulfide gas assessed with AzMC fluorophore. Eight week old male mice then underwent intestinal ischemia for 60 mins, after which time, perfusion was restored. BMSCs from each of the above groups were then placed into the mouse abdominal cavity prior to final closure. After 24 hours, mice were reanesthetized and mesenteric perfusion was assessed by Laser Doppler Imaging (LDI). Animals were then sacrificed and intestines excised, placed in formalin, paraffin embedded, and stained with $\mathrm{H} \& \mathrm{E}$. Intestines were then scored with a common mucosal injury grading scale.

Results: PCR confirmed knockdown of conventional $\mathrm{H}_{2} \mathrm{~S}$ producing enzymes (CBS, MPST, $\mathrm{CTH}$ ). Hydrogen sulfide gas was decreased in MPST and CTH transfected cells in normoxic conditions but was not decreased compared to scramble in any of the transfected groups in hypoxic conditions. BMSCs promoted increased mesenteric perfusion at 24 hours postischemia compared to vehicle. Transfected stem cells provided equivalent protection. Histologic injury was improved with BMSCs compared to vehicle. CBS, MPST, and CTH knockdown cell lines did not have any worse histological injury compared to Scramble. 


\section{Conclusion:}

Knocking down conventional $\mathrm{H}_{2} \mathrm{~S}$ producing enzymes only impacted gas production in normoxic conditions. When cells were transfected in hypoxic conditions, as would be expected in the ischemic intestines, hydrogen sulfide gas was not depressed. These data, along with unchanged perfusion and histological injury parameters with conventional enzyme knockdown would indicate that alternative $\mathrm{H}_{2} \mathrm{~S}$ production pathways may be initiated during hypoxic and/or ischemic events.

\section{KEY WORDS}

hydrogen sulfide, bone marrow-derived mesenchymal stromal cells, intestinal ischemia, perfusion, inflammation, small interfering RNA 


\section{INTRODUCTION}

Intestinal ischemia occurs when the mesenteric vasculature becomes acutely occluded. Interrupted blood flow to the intestine leads to cellular damage, bowel necrosis, and mortality rates as high as $55-80 \%(1,2)$. Surviving patients who have undergone extensive intestinal resection may require intestinal transplantation or intravenous nutrition secondary to the inability to absorb appropriate enteral substrates. Medical therapies to counteract the ischemic damage to the intestines are suboptimal, and therefore, novel treatments are desperately needed.

In this regard, stem cell therapy may provide a promising treatment alternative to traditional medications. Stem cells have been utilized for the experimental treatment of several ischemic conditions, including myocardial infarction and stroke $(3,4)$. Our group has previously appreciated that human bone marrow derived mesenchymal stem cells (BMSCs) can also increase survival following intestinal ischemia (5). Improved survival was also linked with improved mesenteric perfusion, less mucosal injury, and altered inflammatory cytokines.

It is likely that stem cells provide protection via the release of paracrine mediators (6). Hydrogen sulfide $\left(\mathrm{H}_{2} \mathrm{~S}\right)$, long considered a toxic gas, has received considerable attention of late as an autocrine and paracrine mediator of a variety of physiological functions including cytoprotection, vasodilation and as a stimulus for angiogenesis (7-12). Cellular $\mathrm{H}_{2} \mathrm{~S}$ production is also increased by hypoxia $(13,14)$ which would promote autocrine and paracrine signaling (15). This not only makes $\mathrm{H}_{2} \mathrm{~S}$ metabolism an attractive candidate for oxygen sensing (16), but it also suggests that the hypoxic environment of ischemic intestinal tissue would increase $\mathrm{H}_{2} \mathrm{~S}$ production by incipient stem cells, thereby triggering a number of intracellular cascades to promote adaptation to low oxygen environments. This increase in 
$\mathrm{H}_{2} \mathrm{~S}$ would also help protect and sustain the stem cells themselves, which has previously been demonstrated (17-19).

Hydrogen sulfide gas is produced through both conventional and unconventional pathways. The conventional, and more often studied pathways, include three different parallel enzyme systems: cystathionine- $\beta$-synthase (CBS), cystathionine lyase (CSE) and 3mercaptopyruvate sulfurtransferase (MPST) (20) (Figure 1). CBS is generally considered to be the predominant enzyme in the brain, CSE in the heart and vasculature, and MPST in the endothelium, vascular smooth muscle, and the brain (21). Due to the difficulties in measuring $\mathrm{H}_{2} \mathrm{~S}$ gas directly in biological systems, these three enzymes have been accepted as markers of cellular production of $\mathrm{H}_{2} \mathrm{~S}(20,22)$.

It is unknown if hydrogen sulfide is a vital paracrine factor in stem cell mediated intestinal protection or if the conventional $\mathrm{H}_{2} \mathrm{~S}$ producing enzymes play a role in this protection. We therefore hypothesized that hydrogen sulfide gas produced via conventional pathways would be a critical paracrine factor in stem cell mediated intestinal protection following intestinal ischemia and reperfusion (I/R) injury.

\section{MATERIALS AND METHODS}

\section{$\underline{\text { Cell Culture }}$}

Human BMSCs were obtained from Dr. Darwin Prokop's NIH funded lab at Texas A\&M University where they procure, purify, and verify BMSCs from human subjects. BMSCs were reported to meet MSC defining criteria (23). BMSCs were cultured in MesenPRO RSTM Basal Medium for mesenchymal stem cells (Life Technologies, Grand Island, NY) with MesenPro RSTM Growth Supplement. Cells were cultured in $225 \mathrm{~cm}^{2}$ polystyrene culture flasks at $37^{\circ} \mathrm{C}$ in a humidified atmosphere of $5 \% \mathrm{CO}_{2}$ in air. Once cells reached $90 \%$ confluency they were lifted from the flask with TrypLE Express (Life 
Technologies), and passaged to expand primary cultures or used in experimentation. BMSCs were used between passages 4-8. A fluorescent automated cell counter was used to count cells (Luna ${ }^{\mathrm{TM}}$ Automated Cell Counter, Logos Biosystems Inc., Annandale, VA).

\section{Transfection Method with RNA Interference}

For siRNA transfection protocol, BMSCs were cultured to $90 \%$ confluency. Once cells were confluent they were lifted from flasks with TrypLE Express and counted using our automated cell counter. Cells ( $\sim 2.25$ million) were then plated onto a $225 \mathrm{~cm}^{2}$ polystyrene culture flask and incubated at $37^{\circ} \mathrm{C}$ with $5 \% \mathrm{CO}_{2}$ overnight. The next day, cells were then transfected for 24 hours in serum-free media with siRNA against CBS (Dharmacon ${ }^{\mathrm{TM}}$ human CBS ON-TARGETplus SMARTpool \#L-008617-00), CTH (Dharmacon ${ }^{\mathrm{TM}}$ human CTH ONTARGETplus SMARTpool \#L-003481-00), MPST (Dharmacon ${ }^{\mathrm{TM}}$ human MPST ONTARGETplus SMARTpool \#L-010119-00), or scrambled sequences (Dharmacon ${ }^{\mathrm{TM}}$ ONTARGETplus Control Pool \#D-001810-10-20) using a lipofectamine based transfection reagent (Dharmacon ${ }^{\mathrm{TM}}$ Dharmafect ${ }^{\mathrm{TM}} 1$ Transfection Reagent \#T-2001-02, Gene Expression and Gene Editing, GE Healthcare, Lafayette, CO, USA) per manufacturer's instructions. The cells were incubated for an additional 24 hours in normal growth conditions and were subsequently used for animal experimentation. Knockdown of mRNA was confirmed by RTPCR with band intensities compared to the housekeeping gene, glyceraldehyde-3-phosphate dehydrogenase. Primer sequences are listed in Table 1.

\section{$\underline{\text { In vitro } \mathrm{H}_{2}} \underline{\text { S relative quantification }}$}

Cells were plated at a density of 10,000 cells per well in 96-well plates with gaspermeable bottoms (Coy Laboratory Products Inc., Grass Lake, MI) and grown to 80-95\% confluency. The cells were then transfected and treated with the $\mathrm{H}_{2} \mathrm{~S}$-specific fluorophore 7azido-3-methylcoumarin (AzMC, $25 \mathrm{uM}$ : $\lambda \mathrm{ex}=365 \mathrm{~nm}$ and $\lambda \mathrm{em}=450 \mathrm{~nm}$; Millipore Sigma, St. 
Louis, MO). AzMC is an irreversible fluorophore that provides a cumulative index of $\mathrm{H}_{2} \mathrm{~S}$ production. Fluorescence was measured on a SpectraMax M5e plate reader (Molecular Devices, Sunnyvale, CA) according to manufacturer's recommendations and the cells were then placed in normoxia $\left(21 \% \mathrm{O}_{2}, 5 \% \mathrm{CO}_{2}\right.$, and $\mathrm{N}_{2}$ balance $)$ or hypoxia $\left(5 \% \mathrm{O}_{2}, 5 \% \mathrm{CO}_{2}\right.$, and $\mathrm{N}_{2}$ balance) to mimic in vivo conditions for up to 24 hours in a model 856 HYPO hypoxia chamber (Plas Labs, Inc., Lansing, MI) at $37^{\circ} \mathrm{C}$. The plates were removed at timed intervals, and fluorescence was measured before returning the plates to back to the culture incubator. Baseline $\mathrm{H}_{2} \mathrm{~S}$ concentrations were subtracted from final concentrations and normalized to non-transfected control BMSCs. Experiments were repeated three times (Total N=40/group) and data are presented as folds of control.

\section{$\underline{\text { Murine Intestinal I/R Model }}$}

Experimental protocols and animal use were approved by the Indiana University Institutional Animal Care and Use Committee. Wild-type adult male mice (C57BL/6J, Stock No: 00664, 8-12 weeks; Jackson Laboratory, Bar Harbor, ME) underwent at least 48 hours of acclimation to the new environment prior to experimentation. Murine animals were provided normal chow and water and kept in 12 light/12 dark cycle housing.

Mice were anesthetized using 3\% isoflurane followed by maintenance at $1.5 \%$ isoflurane in oxygen. A heating pad was used to achieve temperature homeostasis and the abdomen was prepped using a hair removal lotion followed by sterile preparation with $70 \%$ ethanol and betadine. To account for intra-operative fluid losses, one milliliter of $0.9 \%$ normal saline was injected subcutaneously pre-operatively. All animals were given analgesia (1mg/kg buprenorphine and $5 \mathrm{mg} / \mathrm{kg}$ carprofen) by subcutaneous injection preoperatively.

Under sterile conditions, a midline laparotomy was performed and the intestines were eviscerated. The base of the superior mesenteric artery was identified and clamped 
using an atraumatic microvascular clamp as we have previously described (24). The intestines were then placed back into the abdominal cavity and the abdomen was temporarily closed using silk suture to prevent evaporative losses. Following 60 minutes of intestinal ischemia, the abdomen was reopened and the atraumatic clamp was removed. The abdominal fascia and skin were then closed in a two-layer fashion with silk suture. Prior to complete abdominal closure the animals underwent intraperitoneal injection with $250 \mu \mathrm{L}$ of phosphate buffered saline (PBS; vehicle control) or 2 million BMSCs suspended in $250 \mu \mathrm{L}$ of PBS from one of the following treatment groups: 1) BMSCs, 2) BMSCs transfected with negative control siRNA (Scramble), 3) BMSCs transfected with CBS siRNA, 4) BMSCs transfected with MPST siRNA, or 5) BMSCs transfected with CTH siRNA. Antibiotic ointment was applied to the abdominal incision following complete closure. Following surgery, animals were placed in a cage on a heating pad and allowed to awaken. Once fully recovered, animals were returned to animal housing. A single surgeon (ARJ) performed the abdominal surgeries, perfusion analysis, and stem cell infusions in all animals.

\section{$\underline{\text { Perfusion Analysis }}$}

Perfusion was analyzed using a Laser Doppler perfusion Imager (LDI; Moor Instruments, Wilmington, DE) as previously described (24). Images were acquired at baseline, at the initial clamping of the superior mesenteric artery, and 24 hours after recovery. A region of interest was created around the entirety of exposed intestines to obtain a flux mean perfusion within this region. Three images were acquired at each time point and averaged. Perfusion data was expressed as a percentage of baseline (mean \pm $\mathrm{SEM})(\mathrm{N}=8 /$ group$)$. After the 24 hour recovery analysis, animals were euthanized with isoflurane overdose and cervical dislocation, and intestinal tissues were explanted for further analysis. 


\section{$\underline{\text { Histology Injury Score }}$}

Intestinal tissues were harvested following euthanasia of experimental groups. Terminal ileums were then explanted and fixed using 4\% paraformaldehyde with subsequent dehydration in $70 \%$ ethanol. Intestines were paraffin-embedded, sectioned, and subsequently stained with hematoxylin and eosin. A histological scoring method of intestinal damage was used as previously described: 0 , no damage; 1 , subepithelial space at the villous tip; 2 , loss of mucosal lining at the villous tip; 3 , loss of less than half of the villous structure; 4 , loss of more than half of the villous structure; and 5, transmural necrosis (25) (26). All histological sections were evaluated by two blinded authors (ARJ, NAD) and scores were averaged $(\mathrm{N}=7$ 8/group, total 14-16 scores). Data were not normally distributed and are expressed as median and interquartile range.

\section{$\underline{\text { Statistical Analysis }}$}

All statistical analysis was done using GraphPad Prism 7 (GraphPad Software, La Jolla, CA). Normalcy of data was assessed by the Shapiro Wilk and KS normality tests. Student's t tests or the Mann-Whitney U test were used to compare groups. P-values less than 0.05 were considered statistically significant.

\section{RESULTS}

$\underline{\text { siRNA Transfection and its effects on } \mathrm{H}_{2}}$ S production

In normoxic conditions, transfection of CBS, MPST, and CTH siRNAs effectively decreased mRNA levels of these enzymes (Figure 2A). When $\mathrm{H}_{2} \mathrm{~S}$ gas was measured, significant knockdown in gas production was seen with MPST and CTH transfection, but not with CBS (Figure 2B). 
In an attempt to mimic the in vivo ischemic environment during in vitro transfection, separate groups of BMSCs were cultured in hypoxia. In these conditions, there was still appropriate knockdown of CBS, MPST, and CTH mRNA with siRNA transfection (Figure $3 \mathrm{~A}$ ), but the amount of $\mathrm{H}_{2} \mathrm{~S}$ gas was no longer depressed in the conventional enzyme knockdown groups compared to Scramble (Figure 3B). These results may suggest activation of alternative pathways for $\mathrm{H}_{2} \mathrm{~S}$ production during hypoxia.

\section{Mesenteric Perfusion}

With use of LDI, intestinal perfusion was obtained at 24 hours following IR injury. Vehicle treated animals had significantly lower perfusion levels $(26.4 \% \pm 5.3)$ compared to BMSCs $(72.4 \% \pm 9.3, \mathrm{p}=0.0006)$ and Scramble siRNA BMSCs $(50.7 \% \pm 8.0, \mathrm{p}=0.01$ Figure 4A). There was no difference in perfusion between BMSC treated animals and Scramble siRNA BMSC treated animals $(\mathrm{p}=0.1605)$.

In animals treated with BMSCs with siRNA knockdown of conventional H2S enzymes, a depression in perfusion following treatment was not observed compared to Scramble (Figure 4B). Perfusion at 24 hours in these animals were as follows: 1) CBS siRNA knockdown animals $-50.1 \% \pm 6.1 \%, 2$ ) CTH siRNA knockdown animals $-44.7 \% \pm 6.9 \%$, and 3) MPST siRNA knockdown animals $-47.2 \% \pm 3.9 \%$.

\section{$\underline{\text { Histological Injury }}$}

Intestinal mucosal injury scores were noted to be significantly improved in BMSC (1 (IQR 1) and Scramble siRNA BMSC (2 (IQR 1.75)) groups compared to Vehicle (4 (IQR 3)) (Figure 5A). Histology in the Scramble siRNA BMSC group was equivalent to the nontransfected BMSC treated animals. When compared to the Scramble siRNA group, CBS, 
MPST, or CTH knockdown cells did not result in significantly worse histological injury scores (Figure 5B).

\section{$\underline{\text { DISCUSSION }}$}

Hydrogen sulfide gas has recently been proposed as a potent gasotransmitter that may be responsible for the protection of ischemic tissues $(17,27-29) . \mathrm{H}_{2} \mathrm{~S}$ has been observed to act like a free radical scavenger, to protect against cellular apoptosis, and to promote vasodilation (30). Therefore, the paracrine release of $\mathrm{H}_{2} \mathrm{~S}$ from stem cells may be a plausable mechanism of action for BMSCs to promote end organ protection following injury. $\mathrm{H}_{2} \mathrm{~S}$ is endogenously secreted by BMSCs, and therefore, may also serve as a key paracrine gasotransmitter in stem cell mediated intestinal protection (31).

Herein we discovered that hydrogen sulfide gas was reduced when conventional $\mathrm{H}_{2} \mathrm{~S}$ producing enzymes were knocked down during normoxic conditions, but when cells were transfected and then cultured in hypoxia, gas levels were no different between transfected groups. It is known that hypoxia stimulates hydrogen sulfide gas production (32). Under normoxic conditions, CBS and CSE are usually found in the cytosol, while MPST is present in both the cytosol and in the mitochondria. However, during hypoxia, CBS and CTH are transported to the mitochondria/where they can increase $\mathrm{H}_{2} \mathrm{~S}$ production in a matter of minutes due to significantly increased levels of cysteine (16). Additionally, $\mathrm{H}_{2} \mathrm{~S}$ producing enzymes are distributed differently in different cells and tissues (21). Therefore, the observation that $\mathrm{H}_{2} \mathrm{~S}$ was not decreased with CBS knockdown (in spite of adequate mRNA knockdown) might suggest that CBS does not play as crucial of a role in hydrogen sulfide production in stem cells as the other two enzymes. In our study, we did not observe a compensatory increase in the other two conventional enzyme's mRNA when the third enzyme was knocked down. Higher levels of $\mathrm{H}_{2} \mathrm{~S}$ gas in hypoxia in the absence of a 
compensatory increase in the other mRNAs would suggest that the increased gas was due to the activation of unconventional pathways of hydrogen sulfide production (Figure 1).

This concept was also supported in the perfusion and histological data. In the perfusion studies, all of the stem cell groups that underwent transfection provided equivalent protection following intestinal I/R. All these groups had better post-ischemic mesenteric perfusion compared to vehicle, and the CBS, MPST, and CTH knockdown groups had equivalent protection to Scramble. When the intestinal tissue was analyzed for histological injury, both non-transfected BMSC and Scramble BMSC transfected groups had better histological injury scores compared to vehicle. However, CBS, MPST, and CTH knockdown groups were not any worse compared to Scramble groups.

There are other methods of hydrogen sulfide production that have been described that are outside the scope of the three main conventional enzymes of CBS, MPST, and CTH (21). One such unconventional enzyme, catalase, was found to dependently generate $\mathrm{H}_{2} \mathrm{~S}$ from dithiothreitol in both normoxia and hypoxia, concomitantly oxidizing $\mathrm{H}_{2} \mathrm{~S}$ in the presence of oxygen. Catalase has also been shown to generate $\mathrm{H}_{2} \mathrm{~S}$ from garlic oil, diallyltrisulfide, thioredoxin and sulfur dioxide, but not from sulfite, metabisulfite, carbonyl sulfide, cysteine, cystine, glutathione or oxidized glutathione (33). Other unconventional sources of hydrogen sulfide production include acid labile sulfides, mitochondrial complex I, thiosulfates, and volatile organic sulfides (21).

The culmination of our data might suggest that hydrogen sulfide is not an important paracrine factor in stem cell mediated intestinal protection following ischemia. However, knowing that application of exogenous hydrogen sulfide has elicited protection after intestinal injury $(34,35)$, that hydrogen sulfide is an important component of stem cell mediated intestinal protection in models of necrotizing enterocolitis (36), that multiple avenues of production exist (21), that it is nearly impossible to block all aspects of 
production, and that it is a sensor for hypoxia (16), would all lead us to consider an alternative hypothesis. We would postulate that the reason we see similar protective effects when nontransfected stem cells or stem cells with knockdown of $\mathrm{H}_{2} \mathrm{~S}$ producing enzymes are used is that hydrogen sulfide gas production is increased during ischemia via unconventional methods within the hypoxic environment. It is likely these mechanisms of $\mathrm{H}_{2} \mathrm{~S}$ gas production that drive stem cell mediated intestinal protection.

\section{LIMITATIONS}

The superior mesenteric artery (SMA) ligation model of intestinal I/R does not model clinical intestinal ischemia to its fullest. Although complete small bowel ischemia is possible secondary to SMA thrombus or embolus, the majority of intestinal ischemic episodes are due to segmental intestinal ischemia, such as may be seen with adhesive bowel obstructions or incarcerated hernias. Nonetheless, this model mimics the most severe form of intestinal ischemia, and therefore, is likely considered the best animal model available to test the effectiveness of novel therapies.

An additional limitation is that we did not combine all three $\mathrm{H}_{2} \mathrm{~S}$ producing enzymes together in an attempt to simultaneously knockdown all enzymes. This would have required using $1 / 3$ the dose of siRNA for each enzyme in order to match the total siRNA amount in the negative control Scramble group. This would have resulted in less siRNA for each enzyme being used than what was used in the single knockdown groups. We could also have used a second negative control (Scramble) in which we used three times the amount of Sramble siRNA and then used a triple knockdown in which each component would have matched their single knockdown counterpart, but we felt that this would have been too toxic to cells.

Furthermore, human cells were utilized in this study as a preclinical assessment in a mouse model of intestinal I/R injury. Cross species transplantation usually results in acute 
rejection and largely does not elicit effective results within immunocompetent hosts. However, mesenchymal stem cells, including those derived from bone marrow, have specific immunomodulatory properties that suppress T-lymphocyte proliferation and allow them to be transplanted across species $(37,38)$.

Finally, other cytokines and cell populations within the in vivo environment that are absent within the in vitro environment likely interact and affect the transplanted stem cells. The exact interactions and effects on the stem cells from these other factors are difficult to predict and may play a role in the study outcomes. .

\section{CONCLUSION}

BMSCs have been shown to be protective to the intestines in many studies.

Furthermore, it is likely that stem cells provide protection through the release of one, or likely multiple, paracrine mediators. This study suggests that either stem cells do not utilize hydrogen sulfide as a key paracrine mediator in intestinal protection, or more likely, that there are multiple avenues to generate hydrogen sulfide that have the ability to compensate for the more traditionally studied $\mathrm{H}_{2} \mathrm{~S}$ producing enzymes when they are blocked or knocked down. 


\section{REFERENCES:}

1. Chang RW, Chang JB and Longo WE: Update in management of mesenteric ischemia. World J Gastroenterol 12(20):3243-7, 2006.

2. Schoots IG, Koffeman GI, Legemate DA, Levi M and van Gulik TM: Systematic review of survival after acute mesenteric ischaemia according to disease aetiology. Br J Surg 91(1):17-27, 2004.

3. Meng D, Han S, Jeong IS and Kim SW: Interleukin 10-Secreting MSCs via TALENMediated Gene Editing Attenuates Left Ventricular Remodeling after Myocardial Infarction. Cell Physiol Biochem 52(4):728-741, 2019.

4. Huang P, Freeman WD, Edenfield BH, Brott TG, Meschia JF and Zubair AC: Safety and Efficacy of Intraventricular Delivery of Bone Marrow-Derived Mesenchymal Stem Cells in Hemorrhagic Stroke Model. Sci Rep 9(1):5674, 2019.

5. Markel TA, Crafts TD, Jensen AR, Hunsberger EB and Yoder MC: Human mesenchymal stromal cells decrease mortality after intestinal ischemia and reperfusion injury. J Surg Res 199(1):56-66, 2015.

6. Crisostomo PR, Wang M, Markel TA, Lahm T, Abarbanell AM, Herrmann JL and Meldrum DR: Stem cell mechanisms and paracrine effects: potential in cardiac surgery. Shock 28(4):375-83, 2007.

7. Dongo E, Hornyak I, Benko Z and Kiss L: The cardioprotective potential of hydrogen sulfide in myocardial ischemia/reperfusion injury (review). Acta Physiol Hung 98(4):369-81, 2011.

8. Hosoki R, Matsuki N and Kimura H: The possible role of hydrogen sulfide as an endogenous smooth muscle relaxant in synergy with nitric oxide. Biochem. Biophys. Res. Commun 237(3):527-531, 1997. 
9. Marutani E, Sakaguchi M, Chen W, Sasakura K, Liu J, Xian M, Hanaoka K, Nagano T and Ichinose F: Cytoprotective effects of hydrogen sulfide-releasing -methyl-D-aspartate receptor antagonists are mediated by intracellular sulfane sulfur. Medchemcomm 5(10):1577$1583,2014$.

10. Polhemus DJ, Kondo K, Bhushan S, Bir SC, Kevil CG, Murohara T, Lefer DJ and Calvert JW: Hydrogen sulfide attenuates cardiac dysfunction after heart failure via induction of angiogenesis. Circ. Heart Fail 6(5):1077-1086, 2013.

11. Yang G, Wu L, Jiang B, Yang W, Qi J, Cao K, Meng Q, Mustafa AK, Mu W, Zhang S, et al.: $\mathrm{H}_{2} \mathrm{~S}$ as a physiologic vasorelaxant: hypertension in mice with deletion of cystathionine gamma-lyase. Science 322(5901):587-590, 2008.

12. Coletta C, Modis K, Szczesny B, Brunyanszki A, Olah G, Rios EC, Yanagi K, Ahmad A, Papapetropoulos A and Szabo C: Regulation of Vascular Tone, Angiogenesis and Cellular Bioenergetics by the 3-Mercaptopyruvate Sulfurtransferase/H2S Pathway: Functional Impairment by Hyperglycemia and Restoration by DL-alpha-Lipoic Acid. Mol Med 21:1-14, 2015.

13. Olson KR, Dombkowski RA, Russell MJ, Doellman MM, Head SK, Whitfield NL and Madden JA: Hydrogen sulfide as an oxygen sensor/transducer in vertebrate hypoxic vasoconstriction and hypoxic vasodilation. J. Exp. Biol 209:4011-4023, 2006.

14. Olson KR, Whitfield NL, Bearden SE, J. SL, Nilson E, Gao Y and Madden JA: Hypoxic pulmonary vasodilation: A paradigm shift with a hydrogen sulfide mechanism. Am. J. Physiol Regul. Integr. Comp Physiol 298:R51-R60, 2010.

15. Olson KR: A theoretical examination of hydrogen sulfide metabolism and its potential in autocrine/paracrine oxygen sensing. Respir. Physiol Neurobiol 186:173-179, 2013.

16. Olson KR: Hydrogen sulfide as an oxygen sensor. Antioxid Redox Signal 22(5):377-97, 2015. 
17. Dongo E, Benko Z, Csizmazia A, Marosi G, Grottke A, Jucker M, Schumacher U and Kiss L: H2S preconditioning of human adipose tissue-derived stem cells increases their efficacy in an in vitro model of cell therapy for simulated ischemia. Life Sci 113(1-2):14-21, 2014.

18. Guo Z, Li CS, Wang CM, Xie YJ and Wang AL: CSE/H2S system protects mesenchymal stem cells from hypoxia and serum deprivationinduced apoptosis via mitochondrial injury, endoplasmic reticulum stress and PI3K/Akt activation pathways. Mol. Med. Rep 12(2):2128-2134, 2015.

19. Liu Y, Yang R, Liu X, Zhou Y, Qu C, Kikuiri T, Wang S, Zandi E, Du J, Ambudkar IS, et al.: Hydrogen sulfide maintains mesenchymal stem cell function and bone homeostasis via regulation of $\mathrm{Ca}(2+)$ channel sulfhydration. Cell Stem Cell 15(1):66-78, 2014.

20. Bos EM, van Goor H, Joles JA, Whiteman M and Leuvenink HG: Hydrogen sulfide: physiological properties and therapeutic potential in ischaemia. Br J Pharmacol 172(6):147993, 2015.

21. Olson KR: H2S and polysulfide metabolism: Conventional and unconventional pathways. Biochem Pharmacol 149:77-90, 2018.

22. Olson KR, DeLeon ER and Liu F: Controversies and conundrums in hydrogen sulfide biology. Nitric Oxide 41:11-26, 2014.

23. Dominici M, Le Blanc K, Mueller I, Slaper-Cortenbach I, Marini F, Krause D, Deans R, Keating A, Prockop D and Horwitz E: Minimal criteria for defining multipotent mesenchymal stromal cells. The International Society for Cellular Therapy position statement. Cytotherapy 8(4):315-7, 2006.

24. Jensen AR, Doster DL, Hunsberger EB, Manning MM, Stokes SM, Barwinska D, March KL, Yoder MC and Markel TA: Human Adipose Stromal Cells Increase Survival and 
Mesenteric Perfusion Following Intestinal Ischemia and Reperfusion Injury. Shock 46(1):75$82,2016$.

25. Chiu CJ, McArdle AH, Brown R, Scott HJ and Gurd FN: Intestinal mucosal lesion in low-flow states. I. A morphological, hemodynamic, and metabolic reappraisal. Arch Surg 101(4):478-83, 1970.

26. Watkins DJ, Yang J, Matthews MA and Besner GE: Synergistic effects of HB-EGF and mesenchymal stem cells in a murine model of intestinal ischemia/reperfusion injury. $J$ Pediatr Surg 48(6):1323-9, 2013.

27. Huang X, Gao Y, Qin J and Lu S: The Role of miR-34a in the Hepatoprotective Effect of Hydrogen Sulfide on Ischemia/Reperfusion Injury in Young and Old Rats. PLoS One 9(11):e113305, 2014.

28. Xie YH, Zhang N, Li LF, Zhang QZ, Xie LJ, Jiang H, Li LP, Hao N and Zhang JX: Hydrogen sulfide reduces regional myocardial ischemia injury through protection of mitochondrial function. Mol Med Rep 10(4):1907-14, 2014.

29. Hunter JP, Hosgood SA, Patel M, Furness P, Sayers RD and Nicholson ML: Hydrogen sulfide reduces inflammation following abdominal aortic occlusion in rats. Ann Vasc Surg 29(2):353-60, 2015.

30. Vadivel A, Alphonse RS, Ionescu L, Machado DS, O'Reilly M, Eaton F, Haromy A, Michelakis ED and Thebaud B: Exogenous hydrogen sulfide (H2S) protects alveolar growth in experimental O2-induced neonatal lung injury. PLoS One 9(3):e90965, 2014.

31. Fox B, Schantz JT, Haigh R, Wood ME, Moore PK, Viner N, Spencer JP, Winyard PG and Whiteman M: Inducible hydrogen sulfide synthesis in chondrocytes and mesenchymal progenitor cells: is H2S a novel cytoprotective mediator in the inflamed joint? J Cell Mol Med 16(4):896-910, 2012. 
32. Peng YJ, Nanduri J, Raghuraman G, Souvannakitti D, Gadalla MM, Kumar GK, Snyder SH and Prabhakar NR: H2S mediates O2 sensing in the carotid body. Proc Natl Acad Sci U S A 107(23):10719-24, 2010.

33. Olson KR, Gao Y, DeLeon ER, Arif M, Arif F, Arora N and Straub KD: Catalase as a sulfide-sulfur oxido-reductase: An ancient (and modern?) regulator of reactive sulfur species (RSS). Redox Biol 12:325-339, 2017.

34. Drucker NA, Jensen AR, Te Winkel JP and Markel TA: Hydrogen Sulfide Donor GYY4137 Acts Through Endothelial Nitric Oxide to Protect Intestine in Murine Models of Necrotizing Enterocolitis and Intestinal Ischemia. J Surg Res 234:294-302, 2019.

35. Jensen AR, Drucker NA, Khaneki S, Ferkowicz MJ and Markel TA: Hydrogen sulfide improves intestinal recovery following ischemia by endothelial nitric oxide-dependent mechanisms. Am J Physiol Gastrointest Liver Physiol 312(5):G450-G456, 2017.

36. Drucker NA, Te Winkel JP, Shelley WC, Olson KR and Markel TA: Inhibiting hydrogen sulfide production in umbilical stem cells reduces their protective effects during experimental necrotizing enterocolitis. J Pediatr Surg, 2019.

37. Lin CS, Lin G and Lue TF: Allogeneic and xenogeneic transplantation of adiposederived stem cells in immunocompetent recipients without immunosuppressants. Stem Cells Dev 21(15):2770-8, 2012.

38. Corradi-Perini C, Santos TM, Camara NOS, Riella MC and Aita CAM: Cotransplantation of Xenogeneic Bone Marrow-derived Mesenchymal Stem Cells Alleviates Rejection of Pancreatic Islets in Non-obese Diabetic Mice. Transplant Proc 49(4):902-905, 2017. 


\section{FIGURE LEGENDS}

Figure 1. Conventional and Unconventional Methods of Producing $\mathrm{H}_{2} \mathrm{~S}$. Hydrogen

sulfide is produced via three conventional enzymes, CBS, MPST, and CTH. It is also produced through a number of unconventional pathways including through catalase, volatile organic sulfides, and mitochondrial complex I.

\section{CONVENTIONAL}

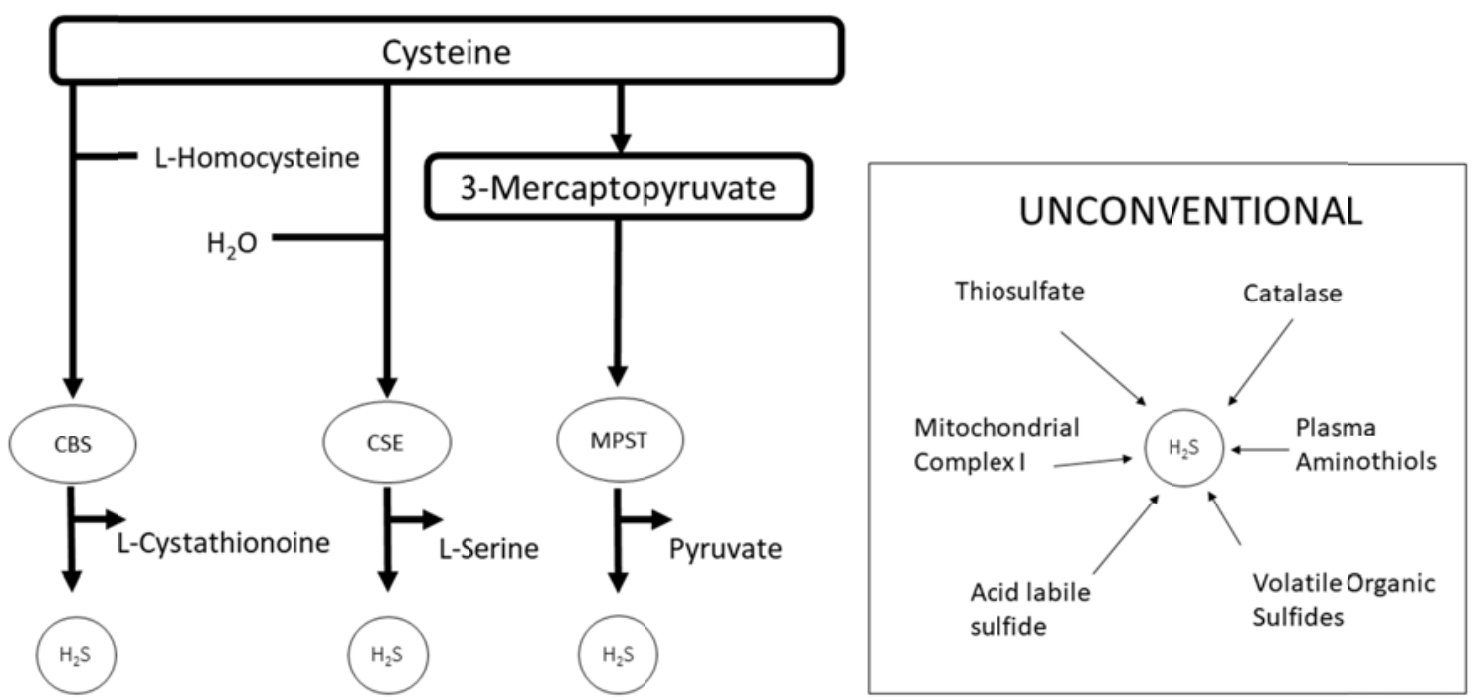


Figure 2. Hydrogen sulfide gas is decreased in normoxic conditions with ablation of conventional $\mathrm{H}_{2} \mathrm{~S}$ producing enzymes. A) Representative PCR blots demonstrating effective decrease in mRNA levels with siRNA transfection. Stem cells were incubated with negative control (Scramble) siRNA, as well as siRNA to CBS, MPST, and CTH. B) Analysis of $\mathrm{H}_{2} \mathrm{~S}$ production demonstrates a decrease under normoxic conditions when CTH and MPST siRNAs were used. $*=p<0.05$ vs. Scramble (Total $N=40 /$ group. Experiments were repeated three times and averaged:16+16+8).

\section{NORMOXIA}

A

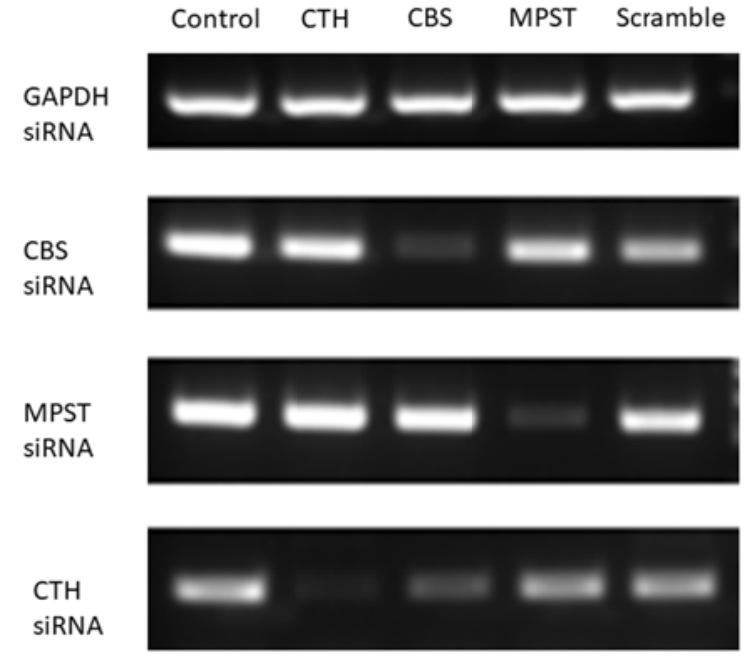

B

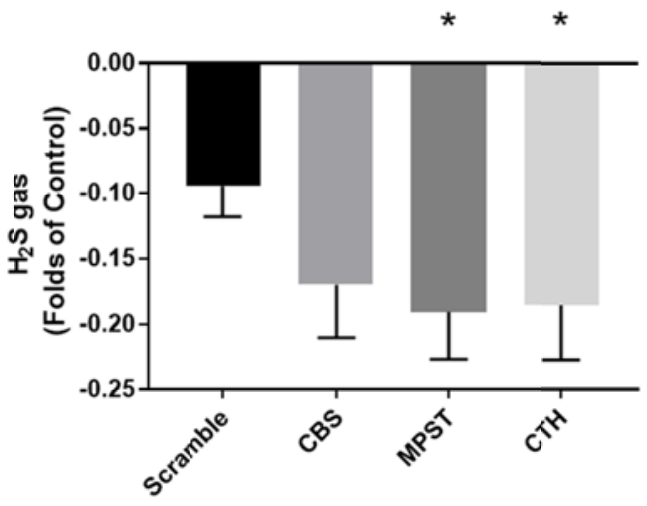


Figure 3. Hydrogen sulfide gas is not decreased in hypoxic conditions with ablation of conventional $\mathrm{H}_{2} \mathrm{~S}$ producing enzymes. A) Representative PCR blots demonstrating effective decrease in mRNA levels with siRNA transfection. Stem cells were incubated with negative control (Scramble) siRNA, as well as siRNA to CBS, MPST, and CTH. B) Analysis of $\mathrm{H}_{2} \mathrm{~S}$ production demonstrates no change in $\mathrm{H}_{2} \mathrm{~S}$ in siRNA knockdown groups compared to Scramble during hypoxia. (Total N=40/group. Experiments were repeated three times and averaged: $16+16+8)$.

\section{HYPOXIA}

A

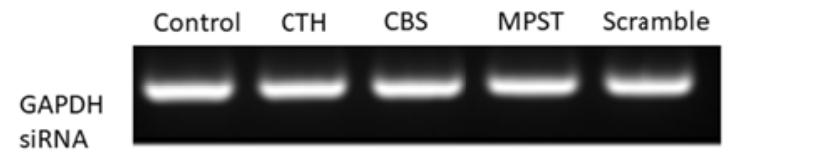

CBS

SiRNA

MPST

SiRNA

CTH siRNA
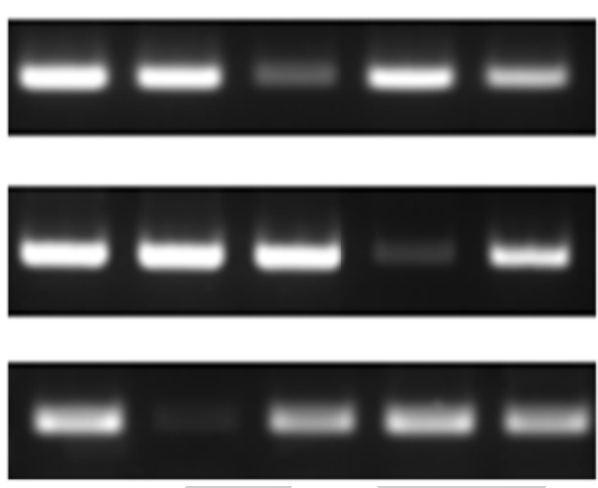

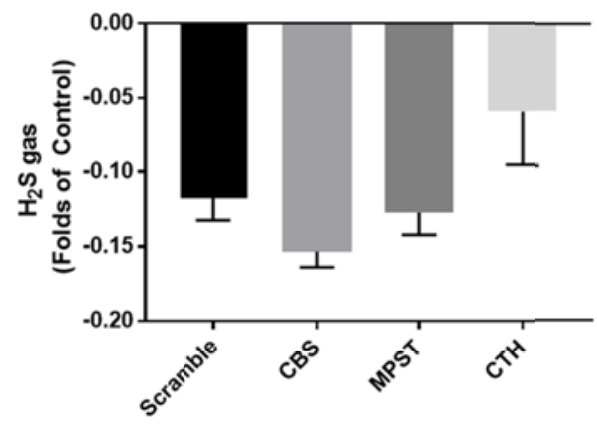


Figure 4. Mesenteric Perfusion. (A) BMSC and Scramble BMSC treated groups improved post-ischemic mesenteric perfusion compared to Vehicle. (B) Knockdown of CBS, MPST, or CTH had no effect on mesenteric perfusion compared to Scramble. $*=p<0.05$ vs. IR+Vehicle. (Total $\mathrm{N}=8$ /group)

A

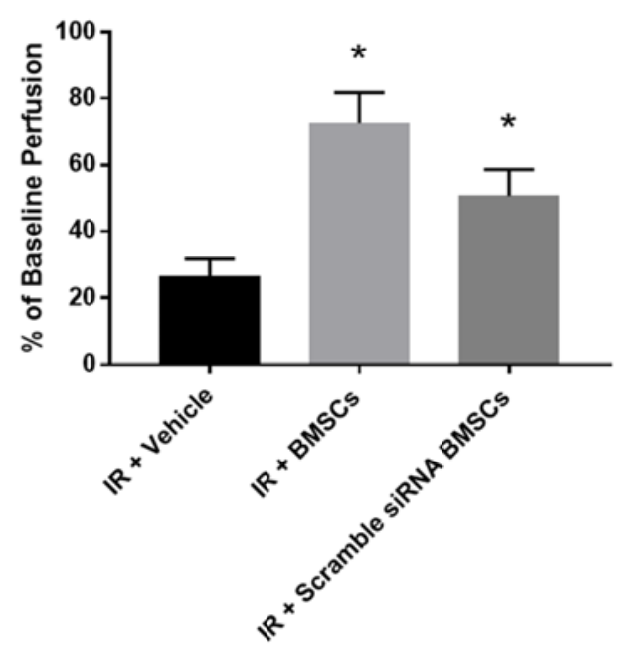

B
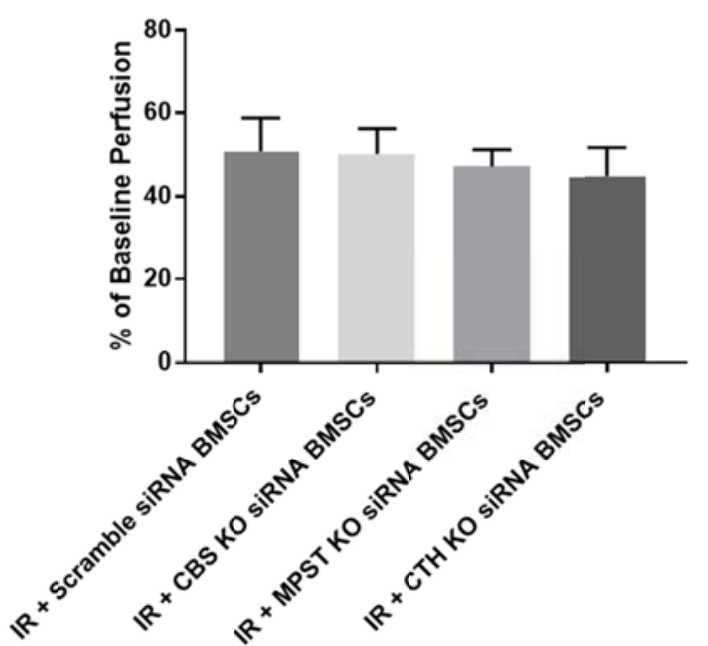
Figure 5. Histological Injury. (A) BMSC and Scramble BMSC treated groups improved post-ischemic mucosal injury scores compared to Vehicle. (B) Knockdown of CBS, MPST, or CTH had no effect on histologic injury scores compared to Scramble. ${ }^{*}=\mathrm{p}<0.05$ vs. IR+Vehicle, $\#=p<0.05$ vs. IR+BMSC (Total N=7-8/group, total 14-16 scores)

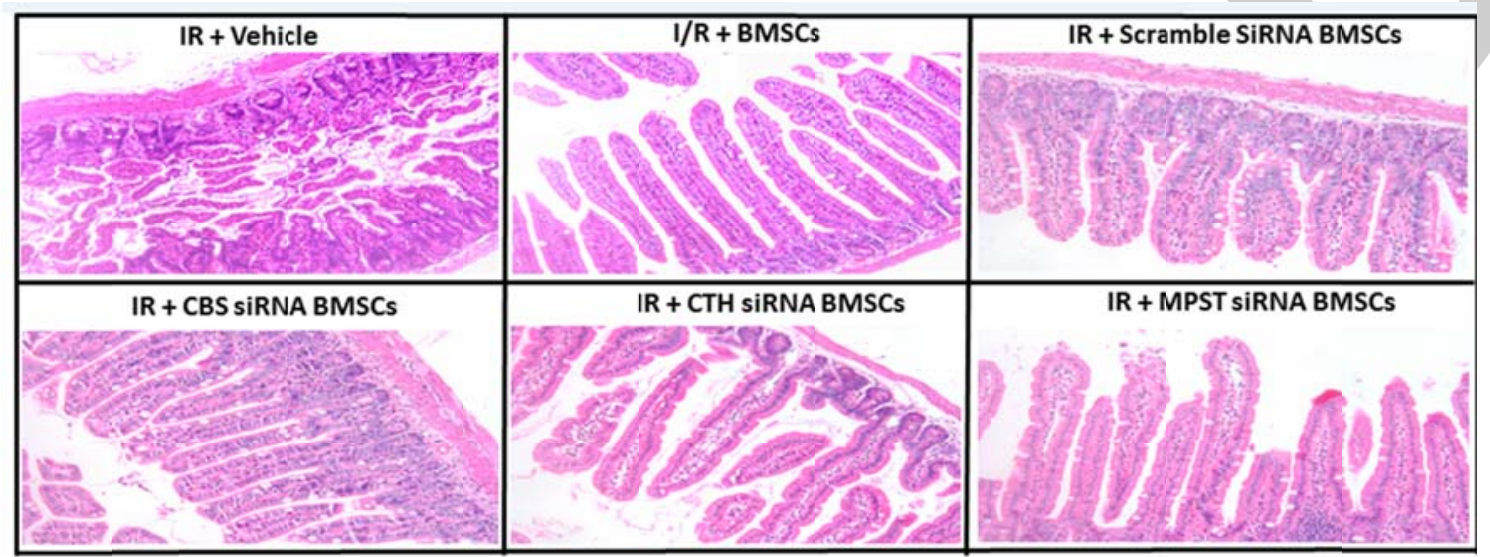

A
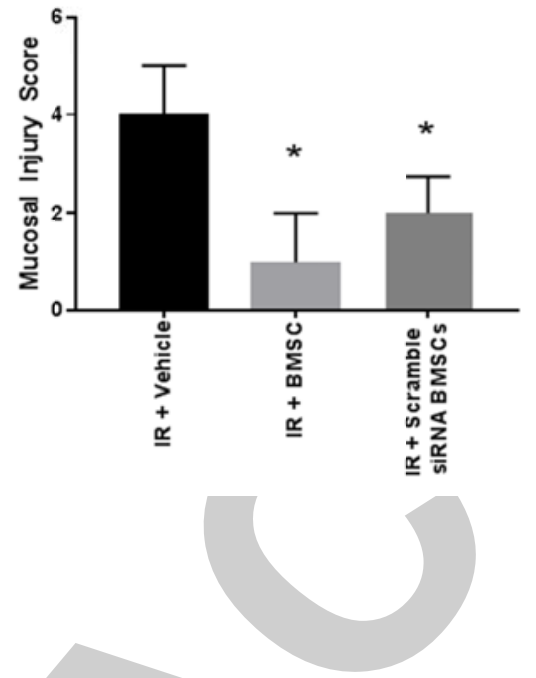

B

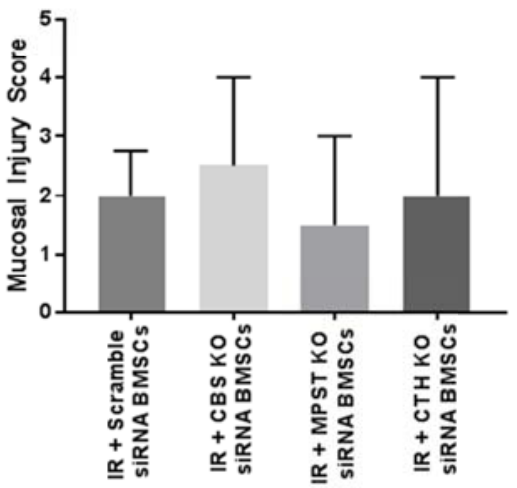

\section{$\underline{\text { TABLES }}$}

Table 1. PCR Primers ( $\left.5^{\prime} \rightarrow 3^{\prime}\right)$

\begin{tabular}{|l|l|l|}
\hline \multirow{2}{*}{ CBS } & Forward & GTCAGACCAAGTTGGCAAAGT \\
\cline { 2 - 3 } & Reverse & CACCCCGAACACCATCTGC \\
\hline \multirow{3}{*}{ CTH } & Forward & CATGAGTTGGTGAAGCGTCAG \\
\cline { 2 - 3 } & Reverse & AGCTCTCGGCCAGAGTAAATA \\
\cline { 2 - 3 } & Forward & CGCCGTGTCACTGCTTGAT \\
\cline { 2 - 3 } GAPDH & Feverse & CAGGTTCAATGCCGTCTCG \\
\cline { 2 - 3 } & Reverse & GGAGCGAGATCCCTCCAAAAT \\
\hline
\end{tabular}

